\title{
Cognitive screening among acute respiratory failure survivors: a cross-sectional evaluation of the Mini-Mental State Examination
}

\author{
Elizabeth R Pfoh ${ }^{1}$, Kitty S Chan ${ }^{1}$, Victor D Dinglas ${ }^{2,3}$, Timothy D Girard ${ }^{4,5,6,7}$, James C Jackson ${ }^{4}$, Peter E Morris ${ }^{8}$, \\ Catherine L Hough ${ }^{9}$, Pedro A Mendez-Tellez ${ }^{2,10}$, E Wesley Ely ${ }^{4,7}$, Minxuan Huang ${ }^{2,3}$, Dale M Needham²,3,11, \\ Ramona O Hopkins ${ }^{12,13,14^{*}}$ and with the NIH NHLBI ARDS Network
}

\begin{abstract}
Introduction: The Mini-Mental State Examination (MMSE) is a common cognitive screening test, but its utility in identifying impairments in survivors of acute respiratory failure is unclear. The purpose of this study was to evaluate MMSE performance versus a concurrently administered detailed neuropsychological test battery in survivors of acute respiratory failure.

Methods: This cross-sectional analysis used data from the ARDSNet Long Term Outcomes Study (ALTOS) and Awakening and Breathing Controlled Trial (ABC). Participants were 242 survivors of acute respiratory failure. The MMSE and detailed neuropsychological tests were administered at 6 and 12 months post-hospital discharge for the ALTOS study, and at hospital discharge, 3 and 12 months for the ABC study. Overall cognitive impairment identified by the MMSE (score <24) was compared to impairments identified by the neuropsychological tests. We also matched orientation, registration, attention, memory and language domains on the MMSE to the corresponding neuropsychological test. Pairwise correlations, sensitivity, specificity, positive and negative predictive values, and agreement were assessed.
\end{abstract}

Results: Agreement between MMSE and neuropsychological tests for overall cognitive impairment was fair (42 to $80 \%$ ). Specificity was excellent ( $\geq 93 \%$ ), but sensitivity was poor (19 to $37 \%$ ). Correlations between MMSE domains and corresponding neuropsychological tests were weak to moderate ( 6 months: $r=0.11$ to $0.28 ; 12$ months: $r=0.09$ to 0.34$)$. The highest correlation between the MMSE and neuropsychological domains was for attention at 6 months $(r=0.28)$ and language at 12 months $(r=0.34)$.

Conclusions: In acute respiratory failure survivors, the MMSE has poor sensitivity in detecting cognitive impairment compared with concurrently administered detailed neuropsychological tests. MMSE results in this population should be interpreted with caution.

\section{Introduction}

Many survivors of acute respiratory failure experience long-term cognitive impairments across a variety of cognitive domains, including attention, memory, mental processing speed and executive function [1-6]. To evaluate such impairments, comprehensive neuropsychological test

\footnotetext{
* Correspondence: mona.hopkins@imail.org

${ }^{12}$ Division of Pulmonary and Critical Care Medicine, Intermountain Medical Center, 5121 Cottonwood Street, Murray, UT 84107, USA

${ }^{13}$ Psychology Department and Neuroscience Center, Brigham Young University, 1022 SWKT, Provo, UT 84602, USA

Full list of author information is available at the end of the article
}

batteries are commonly used [7-11]. However, such batteries require trained personnel, expensive licensing fees and several hours per patient for test administration and scoring. Hence, valid cognitive screening tests that are inexpensive, brief and easy to administer would be invaluable in identifying which survivors may develop long-term cognitive impairment [2]. Furthermore, cognitive screening tests may aid in understanding risk factors and trajectories of cognitive impairments [5,12], and may facilitate the development and evaluation of targeted interventions to address cognitive impairments [13,14].

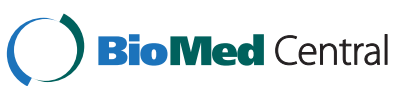

(c) 2015 Pfoh et al. This is an Open Access article distributed under the terms of the Creative Commons Attribution License (http://creativecommons.org/licenses/by/4.0), which permits unrestricted use, distribution, and reproduction in any medium, provided the original work is properly credited. The Creative Commons Public Domain Dedication waiver (http:// creativecommons.org/publicdomain/zero/1.0/) applies to the data made available in this article, unless otherwise stated. 
The Mini-Mental State Examination (MMSE) is a commonly used screening test for cognitive impairment in both clinical practice [15,16], and research [17-24]. Among older adults, the MMSE is the most widely used cognitive screening test, with a pooled sensitivity of $88 \%$ and specificity of $86 \%$ [15]. Moreover, the MMSE has good performance in identifying mild cognitive impairment in older adults [14], identifying subtypes of mild cognitive impairment [25] and predicting cognitive impairment in patients with post-operative delirium [26].

As a result of these favorable performance characteristics, the MMSE has been commonly used to assess cognitive outcomes in critical care populations [17-22,24]. However, the performance of the MMSE has not been specifically evaluated in acute respiratory failure survivors. Understanding whether the MMSE can accurately screen for cognitive impairment in this patient population would provide important new insights. Hence, the objective of this study is to assess whether the MMSE can detect cognitive impairment, as assessed by a concurrently administered, detailed neuropsychological test battery, in survivors of acute respiratory failure. Additionally, this study explored whether the timing of patient follow-up assessment after hospital discharge or patient characteristics influenced the relationship between the MMSE and the neuropsychological test battery.

\section{Methods}

\section{Participants}

We conducted a cross-sectional secondary analysis of data from two prospective studies of acute respiratory failure patients requiring mechanical ventilation in an ICU. The data from the first study came from the National Institutes of Health-funded ARDS Network Long Term Outcomes Study (ALTOS), which evaluated 6 and 12 month outcomes from patients enrolled in multi-site randomized trials conducted by the ARDS Network from July 2008 to May 2012 [19,27-30]. The patients from these trials had similar eligibility criteria and were enrolled from the same study sites during a similar time frame; as such the data were pooled for this study. Patients in the ALTOS study who completed the MMSE and a concurrent neuropsychological test battery at either 6- or 12-month follow-up $(\mathrm{N}=200)$ were included in the current study.

To increase the generalizability of this evaluation, data from a second study were evaluated. The Awaken and Breathing Controlled (ABC) study evaluated long-term neurocognitive outcomes in patients enrolled at a single hospital in Nashville, Tennessee, between October 2003 and March 2006 [31]. Patients from a sub-study of the $\mathrm{ABC}$ study patients were included here [31]. The following baseline and ICU data were obtained: age, gender, race, years of education, employment status, Charlson comorbidity index [32] and psychiatric comorbidity (as described further below), severity of illness, mechanical ventilation duration, and ICU and hospital length of stay.

\section{ALTOS Study}

In the ALTOS study, patients were administered the MMSE and a standardized neuropsychological test battery at 6- and 12-month follow-up [27]. The MMSE was administered via telephone using a validated 26-item version [33], while the neuropsychological battery was administered in person by research assistants who underwent detailed training and quality assurance evaluations by $\mathrm{RH}$. The telephone version of the MMSE differs from the in-person MMSE in that it excludes the following items: 1) A question about orientation to place, which asks 'What floor of the building are we on?'; 2) A question related to following commands which asks the patient to 'close your eyes'; 3) A question related to simple sentence construction that asks the patient to 'write a sentence' 4) A question related to visuospatial construction that asks the patient to 'copy overlapping pentagons'. Additionally, the telephone version uses only one naming item, as opposed to three items in the standard MMSE [33]. The MMSE telephone score was converted to the standard 30-point scale of the standard MMSE using previously published methods [33]. The MMSE assesses overall cognitive impairment based on five cognitive domains: 1) orientation (orientation to time and place), 2) registration (registration of three words), 3) attention (backward spelling of 'WORLD'), 4) memory (recall of three words) and 5) language (naming, repetition and following a three-stage command) [34].

Similar cognitive domains were identified from the neuropsychological test battery, which is made up of widely used neuropsychological tests with known reliability and validity [35-37]. The domains included: 1) orientation from the Neurobehavioral Cognitive Status Examination orientation total score [38]; 2) registration from the Digit Span's raw forward score from the Wechsler Adult Intelligence Scale-Third Edition [39,40]; 3) attention from the Digit Span's total age-adjusted score and the raw forward and backward scores from the Wechsler Adult Intelligence Scale-Third Edition $[39,40]$; 4) memory from the Logical Memory I and Logical Memory II age-adjusted scores from the Wechsler Memory Scale-Third Edition [39,40] and 5) language via the Verbal Fluency test [41]. MMSE scores for each domain were compared to scores for the corresponding neuropsychological test (recognizing there is not necessarily a one-to-one correspondence between the tests in the domains of interest between the MMSE and neuropsychological test battery). We also compared overall cognitive impairment between the MMSE and the neuropsychological test battery. 
Presence of baseline psychiatric comorbidity was present if the patient had any of the following (based on medical chart review): current or past excessive alcohol use, illicit drug use or drug rehabilitation, diagnosis or treatment for psychiatric disorder or documented history of depression or anxiety $[19,42]$. Depression and anxiety were assessed at 6 and 12 months using the Hospital Anxiety and Depression Scale, which provides separate subscale scores for depression and anxiety. Scores of eight or higher indicate probable depression or anxiety $[19,43]$.

\section{$A B C$ study}

In the $\mathrm{ABC}$ study, patients were administered the MMSE and a detailed neuropsychological test battery in person at hospital discharge, and at 3- and 12-month follow-up, by a single neuropsychologist [31]. To examine generalizability of the primary ALTOS study analyses, we evaluated the ability of the MMSE to detect overall cognitive impairment compared to a similar neuropsychological test battery in the ABC study [31]. The ABC study test battery included: 1) Digit Span and Digit Symbol from the Wechsler Adult Intelligence Scale-Third Edition [39,40]; 2) the Rey Auditory Verbal Learning Test (RAVLT) [44]; 3) Rey-Osterreith Complex Figure-Copy and Delayed Recall [45]; 3) Trail Making Test Parts A and B [46] and 4) Verbal Fluency test [47]. We also used data from the $A B C$ study to compare the MMSE attention domain with the Digit Span scores [39].

\section{Statistical analysis}

Cross-sectional data analysis compared MMSE scores with neuropsychological test scores at 3, 6 and 12 months. Cognitive impairment was defined for the MMSE as total scores $<27$ and $<24$, which represent widely used, highly sensitive and specific cutoff scores for cognitive impairment $[17,48]$. Sensitivity and specificity were similar when comparing total MMSE scores of $<27$ and $<24$ versus neuropsychological test scores; therefore, we only report the more conservative cutoff of $<24$. For the neuropsychological test batteries, cognitive impairment was conservatively defined, as done in prior studies [19,27,31], as having at least one cognitive test $\geq 2$ standard deviations below population norms (bottom 2.5\%), or at least two tests $\geq 1.5$ standard deviations below population norms (bottom $6.7 \%$ for both tests). The ability of the MMSE to detect cognitive impairment was evaluated using sensitivity, specificity, positive and negative predictive values, and agreement. The area under the receiver operating characteristics curves was also used to examine the ability of the total MMSE score to discriminate between survivors with and without cognitive impairment, as defined by the neuropsychological test battery [19,27-31].

Pearson correlations were used to examine the relationship between MMSE cognitive domains and the corresponding cognitive domains from the neuropsychological test results. We examined whether these relationships were affected by patient characteristics. Correlations were calculated within relevant patient subgroups defined by age (dichotomized at the mean age of 50 years), gender, education level (dichotomized at the mean of 12 years, that is, high school graduation), depression and anxiety status at 6 and 12 months using the Hospital Anxiety and Depression Scale [43], and pre-existing psychiatric comorbidity prior to acute respiratory failure. Statistical significance was defined as $P \leq 0.05$ and statistical analyses were completed using STATA 12.0 (StataCorp, College Station, TX, USA). This study was conducted in accordance with the amended Declaration of Helsinki. All studies obtained informed consent from participants, and were approved by relevant institutional review boards (ALTOS: Johns Hopkins School of Medicine Institutional Review Board-5 approval number: NA_00013113; ABC: Vanderbilt University and Saint Thomas Hospital Institutional Review Board number: 030803).

\section{Results}

In the ALTOS study, of the 200 eligible patients, 181 and 174 patients completed both the MMSE and the neuropsychological tests at 6 and 12 months, respectively. In the ABC study, 61, 69 and 47 participants completed both the MMSE and neuropsychological tests at hospital discharge, 3 months and 12 months, respectively. Respondents in both studies were predominately white, middle-aged and male, with a mean of approximately 12 years of education (Table 1 ). Pre-ICU psychiatric comorbidity was common, with a prevalence of $42 \%$ in the ALTOS study and $74 \%$ in the ABC study. All patients were mechanically ventilated, and the mean ICU length of stay was 14 and 10 days in the ALTOS and $A B C$ studies, respectively. For the ALTOS study, $12 \%$ and $10 \%$ of patients had MMSE scores $<24$ at 6 and 12 months, respectively; while $38 \%$ and $25 \%$ of patients had cognitive impairments based on the neuropsychological test scores at 6 and 12 months. In the ABC study, the percentage of patients with an MMSE score $<24$ was $33 \%, 17 \%$ and $13 \%$ at discharge, 3 months and 12 months respectively; while $90 \%, 79 \%$ and $71 \%$ had cognitive impairments based on the neuropsychological test scores at these same time points, respectively.

\section{Comparing overall cognitive impairment}

For the ALTOS study, at 6 and 12 months, overall agreement was $67 \%$ and $80 \%$, respectively. Kappa indicated poor concordance after accounting for chance agreement (0.19 and 0.34). At 6 and 12 months, the specificity of the MMSE was excellent (93\% and 97\%, respectively); however, sensitivity was poor $(24 \%$ and $30 \%$, respectively), and positive predictive values $(67 \%$ and $76 \%$, 
Table 1 Patient characteristics

\begin{tabular}{lll}
\hline Characteristic & $\begin{array}{l}\text { ALTOS } \\
(\mathbf{n}=\mathbf{1 8 1})\end{array}$ & $\begin{array}{l}\text { ABC trial } \\
(\mathbf{n}=\mathbf{6 1})\end{array}$ \\
\hline Age, mean (SD) years & 49 & $58(16)$ \\
Male, n (\%) & $90(50)$ & $38(62)$ \\
Education years, mean (SD) & $13(3)$ & $12(3)$ \\
Employed, $n$ (\%) & $93(51)$ & NA \\
Charlson Comorbidity Index, mean (SD) & $1.2(1.7)$ & NA \\
Psychiatric comorbidity, n (\%) & $76(42)$ & $45(74)$ \\
Severity of illness score, mean (SD) & APACHE III: & APACHE II: \\
Mechanical ventilation duration, & $85(25)$ & $28(8)$ \\
mean (SD) days & $11(10)$ & $6(6)$ \\
ICU length of stay, mean (SD) days & $14(11)$ & $10(8)$ \\
Hospital length of stay, mean (SD) days & $22(15)$ & $14(8)$ \\
\hline
\end{tabular}

ICU, Intensive Care Unit; SD, standard deviation; $n$, number.

respectively) and negative predictive values $(67 \%$ and $81 \%$, respectively) were fair to moderate (Table 2 ). The area under the receiver operating characteristics curve was 0.66 (95\% CI: 0.58 to 0.74 ) at 6 months and 0.76 ( $95 \%$ CI: 0.67 to 0.85 ) at 12 months, indicating fair discrimination (Figure 1).

For the ABC study data, overall agreement and kappa scores were low (ranging from 38 to $42 \%$, and 0.09 to 0.12 , respectively) when assessing concordance between screening positive for cognitive impairment on the MMSE, and having cognitive impairment based on the neuropsychological test scores. Specificity and positive predictive value of the MMSE was excellent, at 100\% for all three time points. Sensitivity was poor, ranging from 19 to $37 \%$. Negative predictive values were also poor at all three time points: $13 \%$ at discharge, $25 \%$ at 3 months and $33 \%$ at 12 months (Table 2).

\section{Comparing specific cognitive domains}

Correlations between cognitive domains in the MMSE compared to neuropsychological domains were weak to moderate ( 6 months: 0.11 to 0.28 , Table $3 ; 12$ months: 0.09 to 0.34 , Table 4 ), with the highest correlations observed for attention at 6 months $(r=0.28)$ and language at 12 months $(\mathrm{r}=0.34)$. There was no consistent influence of patient characteristics (gender, age, education level, concurrent depression and anxiety status, or preexisting psychiatric comorbidity) on the correlations in any cognitive domain. The majority of correlations in the subgroup analyses were $\leq 0.30$.

Compared to the ALTOS study, the ABC study data had slightly stronger correlations for attention at all time periods $(<0.5$ versus $<0.3)$. However, in both the ALTOS and $\mathrm{ABC}$ studies, there was no consistent influence of gender and age on correlations between MMSE and neuropsychological attention scores (Table 5).

\section{Discussion}

In cross-sectional analyses of two prospective longitudinal studies of acute respiratory failure survivors, we found that the MMSE had fair to moderate agreement, both for overall cognitive impairment and for specific

Table 2 Overall cognitive impairment at discharge, 3, 6 and 12 months for MMSE versus neuropsychological test battery

\begin{tabular}{|c|c|c|c|c|c|c|c|c|c|c|}
\hline & \multicolumn{2}{|c|}{ Sensitivity } & \multicolumn{2}{|c|}{ Specificity } & \multicolumn{2}{|c|}{ Positive predictive value } & \multicolumn{2}{|c|}{ Negative predictive value } & \multirow[t]{2}{*}{ Kappa (SD) } & \multirow{2}{*}{$\begin{array}{l}\text { Overall } \\
\text { agreement (\%) }\end{array}$} \\
\hline & $\%$ & $(95 \% \mathrm{Cl})$ & $\%$ & $(95 \% \mathrm{Cl})$ & $\%$ & $(95 \% \mathrm{Cl})$ & $\%$ & $(95 \% \mathrm{Cl})$ & & \\
\hline \multicolumn{11}{|c|}{ ALTOS Data } \\
\hline \multicolumn{11}{|l|}{6 Months } \\
\hline MMSE $<24$ & 24 & $(14-35)$ & 93 & $(87-97)$ & 67 & $(45-84)$ & 67 & $(59-74)$ & $0.19(0.06)$ & 67 \\
\hline \multicolumn{11}{|l|}{12 Months } \\
\hline MMSE $<24$ & 30 & $(17-46)$ & 97 & $(92-99)$ & 76 & $(50-93)$ & 81 & $(74-87)$ & $0.34(0.07)$ & 80 \\
\hline \multicolumn{11}{|l|}{ ABC Data } \\
\hline \multicolumn{11}{|l|}{ Discharge } \\
\hline MMSE $<24$ & 37 & $(26-49)$ & 100 & $(59-100)$ & 100 & $(87-100)$ & 13 & $(6-26)$ & $0.09(0.05)$ & 42 \\
\hline \multicolumn{11}{|l|}{3 Months } \\
\hline MMSE $<24$ & 22 & $(12-34)$ & 100 & $(79-100)$ & 100 & $(75-100)$ & 25 & $(15-38)$ & $0.10(0.05)$ & 38 \\
\hline \multicolumn{11}{|l|}{12 Months } \\
\hline MMSE $<24$ & 19 & $(8-35)$ & 100 & $(78-100)$ & 100 & $(59-100)$ & 33 & (20-49) & $0.12(0.07)$ & 42 \\
\hline
\end{tabular}

MMSE, mini-mental status examination; SD standard deviation.

Impairment on neuropsychological test battery = any battery test $\leq 2$ SD or $2+$ tests $\leq 1.5$ SD.

For ALTOS study data: At 6 months: $\mathrm{N}=181$; True positives = 9\%; False positives =4\%; True negatives = 58\%; False negatives = 29\%. At 12 months: $\mathrm{N}=174$; True positives $=7 \%$; False positives $=2 \%$; True negatives $=73 \%$; False negatives $=17 \%$.

For $A B C$ study data: At discharge: $\mathrm{N}=78$; True positives $=33 \%$; False positives $=0 \%$; True negatives $=9 \%$; False negatives $=58 \%$. At 3 months: $\mathrm{N}=76$; True positives $=17 \%$; False positives $=0 \%$; True negatives $=21 \%$; False negatives $=62 \%$. At 12 months: $\mathrm{N}=52 ;$ True positives $=13 \%$; False positives $=0 \%$; True negatives $=29 \%$; False negatives $=58 \%$. 


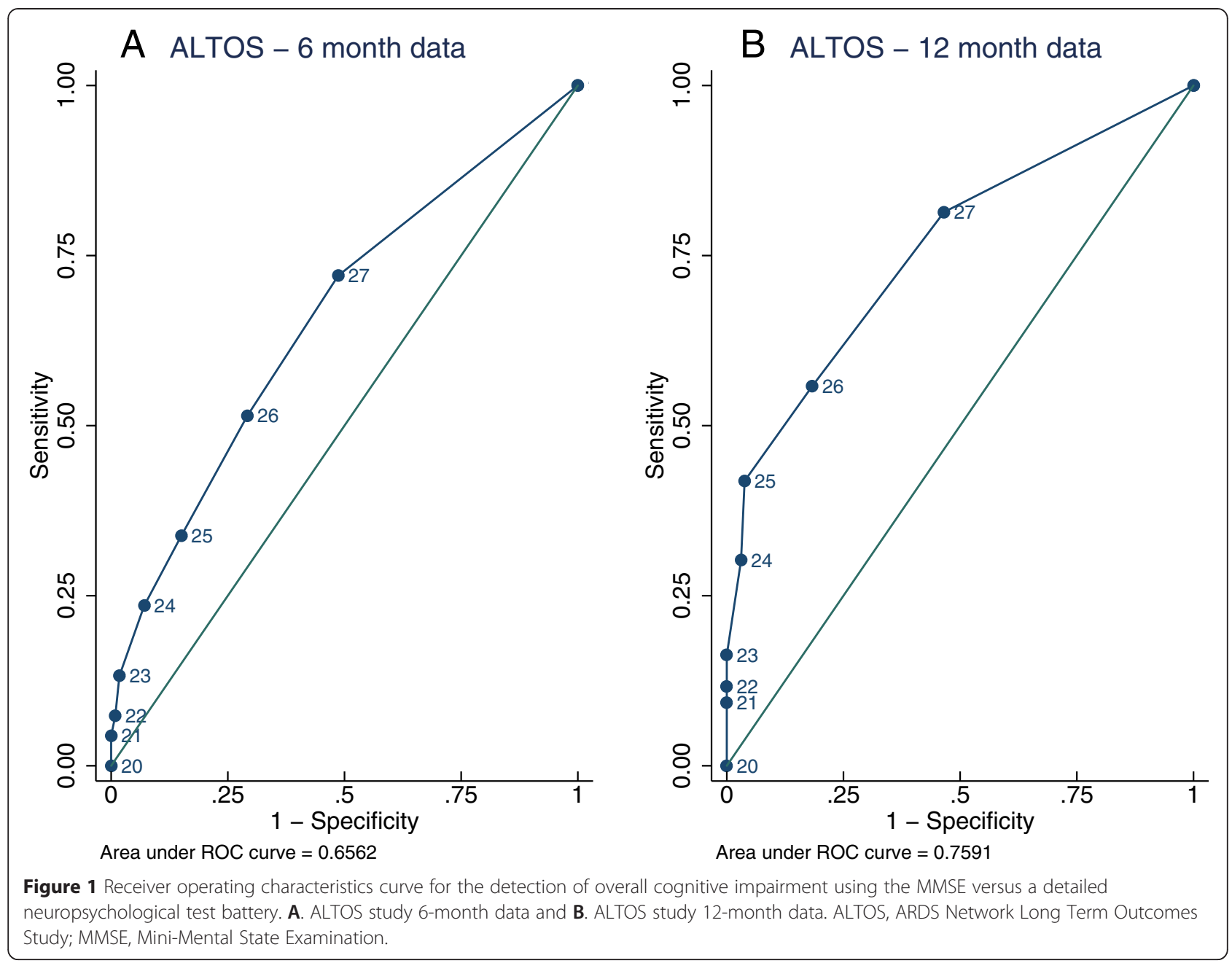

cognitive domains, compared to more detailed neuropsychological tests. These findings were not influenced by patient characteristics or timing of longitudinal followup assessment. Indeed, even when accounting for gender, age, education level, concurrent depression and anxiety status, and pre-existing psychiatric comorbidity prior to ICU admission, MMSE domain scores correlations were weak to moderate with neuropsychological test scores.

The ability of the MMSE to discriminate overall cognitive impairment was only fair based on the receiver operating characteristics curve analysis; expressly, the MMSE had low sensitivity. Even using a conservative cutoff score of $<24$, the MMSE failed to identify a substantial portion of survivors who had cognitive impairment identified on neuropsychological tests, with poor to moderate negative predictive values. Generally, a screening tool should have an area under the ROC curve of at least $>0.8$ to demonstrate excellent diagnostic accuracy [49], and the MMSE failed to meet this threshold at both 6 and 12 months. These results are similar to previous work in cardiac surgery [50] and bariatric surgery [51] patients. Understanding the limited extent of the MMSE's agreement with neuropsychological test scores administered concurrently has important implications. Specifically, screening negative on the MMSE for cognitive impairment does not rule out the presence of cognitive impairment for acute respiratory failure survivors at 3, 6 and 12 months.

There is great interest in screening for cognitive impairment in ICU survivors given the frequent and long-lasting cognitive impairments observed [52]. Our study provides additional evidence that the MMSE may not be a valid cognitive screening tool for use in this patient population. Evaluation of other cognitive screening instruments (such as the Montreal Cognitive Assessment) in this population is needed to determine if they will better identify cognitive impairments [53]. Recent work found the Montreal Cognitive Assessment is more sensitive in accurately differentiating mild cognitive impairment from normal cognitive function [54]. Another approach could include augmenting the MMSE with more targeted instruments. For example, adding a measure of executive function to the MMSE can improve the detection of cognitive deficits [55]. 
Table 3 Correlations of MMSE domain scores with corresponding neuropsychological test by demographic variables at six months

\begin{tabular}{|c|c|c|c|c|c|c|c|c|c|c|c|c|c|c|}
\hline \multirow[t]{2}{*}{ MMSE domain } & \multirow[t]{2}{*}{$\begin{array}{l}\text { Corresponding } \\
\text { neuropsychological } \\
\text { test }\end{array}$} & \multirow{2}{*}{$\begin{array}{l}\text { All patients } \\
(\mathrm{N}=181-183)\end{array}$} & \multicolumn{2}{|l|}{ Gender } & \multicolumn{2}{|l|}{ Age } & \multicolumn{2}{|c|}{ Education } & \multicolumn{2}{|c|}{$\begin{array}{l}\text { Depression } \\
\text { (Cutoff } \geq 8 \text { ) }\end{array}$} & \multicolumn{2}{|c|}{$\begin{array}{l}\text { Anxiety } \\
\text { (Cutoff } \geq 8 \text { ) }\end{array}$} & \multicolumn{2}{|c|}{$\begin{array}{l}\text { Psychiatric } \\
\text { Co-morbidity }\end{array}$} \\
\hline & & & $\begin{array}{l}\text { Male } \\
(n=90)\end{array}$ & $\begin{array}{l}\text { Female } \\
(\mathrm{n}=90-92)\end{array}$ & $\begin{array}{l}<50 \\
(n=82-84)\end{array}$ & $\begin{array}{l}\geq 50 \\
(n=99)\end{array}$ & $\begin{array}{l}\leq H S \\
(n=92)\end{array}$ & $\begin{array}{l}>H S \\
(n=88)\end{array}$ & $\begin{array}{l}\text { No } \\
(n=115)\end{array}$ & $\begin{array}{l}\text { Yes } \\
(n=65)\end{array}$ & $\begin{array}{l}\text { No } \\
(n=107)\end{array}$ & $\begin{array}{l}\text { Yes } \\
(n=74)\end{array}$ & $\begin{array}{l}\text { No } \\
(n=90-91)\end{array}$ & $\begin{array}{l}\text { Yes } \\
(n=88-89)\end{array}$ \\
\hline Orientation & Orientation total & $0.17^{\mathrm{a}}$ & $0.28^{\mathrm{a}}$ & -0.01 & 0.05 & $0.24^{\mathrm{a}}$ & 0.16 & -0.08 & $0.34^{\mathrm{a}}$ & 0.05 & 0.10 & $0.23^{\mathrm{a}}$ & 0.05 & 0.19 \\
\hline \multirow[t]{3}{*}{ Registration } & DS total score & $0.16^{\mathrm{a}}$ & 0.15 & 0.16 & 0.11 & 0.20 & 0.25 & 0.10 & $0.23^{\mathrm{a}}$ & 0.03 & $0.24^{\mathrm{a}}$ & 0.08 & 0.11 & 0.20 \\
\hline & DS forward & $0.16^{\mathrm{a}}$ & $0.23^{\mathrm{a}}$ & 0.09 & 0.09 & $0.21^{\mathrm{a}}$ & $0.31^{\mathrm{a}}$ & 0.03 & $0.25^{\mathrm{a}}$ & 0.00 & $0.34^{\mathrm{a}}$ & 0.01 & 0.18 & 0.11 \\
\hline & DS backward & 0.13 & 0.02 & 0.21 & 0.11 & 0.13 & 0.13 & 0.12 & $0.19^{\mathrm{a}}$ & 0.01 & 0.15 & 0.10 & 0.01 & 0.23 \\
\hline \multirow[t]{3}{*}{ Attention } & DS total score & $0.28^{\mathrm{a}}$ & $0.42^{\mathrm{a}}$ & 0.03 & $0.29^{a}$ & $0.26^{\mathrm{a}}$ & $0.32^{\mathrm{a}}$ & 0.08 & $0.26^{\mathrm{a}}$ & $0.27^{\mathrm{a}}$ & $0.24^{\mathrm{a}}$ & $0.32^{\mathrm{a}}$ & $0.26^{\mathrm{a}}$ & $0.29^{\mathrm{a}}$ \\
\hline & DS forward & $0.24^{\mathrm{a}}$ & $0.33^{\mathrm{a}}$ & 0.02 & $0.30^{\mathrm{a}}$ & $0.18^{\mathrm{a}}$ & $0.25^{\mathrm{a}}$ & 0.07 & $0.23^{\mathrm{a}}$ & 0.23 & $0.27^{\mathrm{a}}$ & 0.20 & $0.26^{\mathrm{a}}$ & 0.21 \\
\hline & DS backward & $0.26^{\mathrm{a}}$ & $0.42^{a}$ & 0.00 & $0.23^{\mathrm{a}}$ & $0.28^{\mathrm{a}}$ & $0.32^{\mathrm{a}}$ & 0.05 & $0.27^{\mathrm{a}}$ & 0.22 & 0.14 & $0.36^{\mathrm{a}}$ & 0.20 & $0.32^{\mathrm{a}}$ \\
\hline \multirow[t]{2}{*}{ Memory } & LM I & 0.13 & 0.07 & $0.23^{*}$ & 0.12 & 0.15 & 0.15 & 0.06 & 0.08 & 0.19 & $0.21^{\mathrm{a}}$ & 0.01 & 0.17 & 0.12 \\
\hline & LM II & 0.10 & 0.00 & 0.20 & 0.08 & 0.15 & 0.13 & 0.00 & 0.04 & 0.17 & $0.20^{\mathrm{a}}$ & -0.08 & 0.14 & 0.09 \\
\hline Language & COWA & $0.16^{\mathrm{a}}$ & $0.24^{\mathrm{a}}$ & 0.08 & 0.04 & $0.22^{\mathrm{a}}$ & $0.22^{\mathrm{a}}$ & 0.10 & 0.10 & 0.16 & 0.10 & 0.21 & 0.15 & 0.18 \\
\hline
\end{tabular}

MMSE, mini-mental status examination; COWA, controlled oral word association; DS, digit span; LM, logical memory, HS, high school.

${ }^{\mathrm{a}} P \leq 0.05$. 
Table 4 Correlations of MMSE domain scores with corresponding neuropsychological test by demographic variables at 12 months

\begin{tabular}{|c|c|c|c|c|c|c|c|c|c|c|c|c|c|c|}
\hline \multirow[t]{2}{*}{ MMSE domain } & \multirow[t]{2}{*}{$\begin{array}{l}\text { Corresponding } \\
\text { neuropsychological } \\
\text { test }\end{array}$} & \multirow{2}{*}{$\begin{array}{l}\begin{array}{l}\text { All } \\
\text { patients }\end{array} \\
(\mathrm{N}=173- \\
174)\end{array}$} & \multicolumn{2}{|l|}{ Gender } & \multicolumn{2}{|l|}{ Age } & \multicolumn{2}{|l|}{ Education } & \multicolumn{2}{|l|}{$\begin{array}{l}\text { Depression } \\
\text { (Cutoff } \geq 8)\end{array}$} & \multicolumn{2}{|l|}{$\begin{array}{l}\text { Anxiety } \\
\text { (Cutoff } \geq 8 \text { ) }\end{array}$} & \multicolumn{2}{|c|}{$\begin{array}{l}\text { Psychiatric } \\
\text { Co-morbidity }\end{array}$} \\
\hline & & & $\begin{array}{l}\text { Male } \\
(n=83)\end{array}$ & $\begin{array}{l}\text { Female } \\
(n=90-91)\end{array}$ & $\begin{array}{l}<50 \\
(n=78)\end{array}$ & $\begin{array}{l}\geq 50 \\
(n=95-96)\end{array}$ & $\begin{array}{l}\leq \mathrm{HS} \\
(\mathrm{n}=88-89)\end{array}$ & $\begin{array}{l}>\mathrm{HS} \\
(\mathrm{n}=83)\end{array}$ & $\begin{array}{l}\text { No } \\
(n=117-118)\end{array}$ & $\begin{array}{l}\text { Yes } \\
(n=57-56)\end{array}$ & $\begin{array}{l}\text { No } \\
(n=106-107)\end{array}$ & $\begin{array}{l}\text { Yes } \\
(n=67-68)\end{array}$ & $\begin{array}{l}\text { No } \\
(n=87-88)\end{array}$ & $\begin{array}{l}\text { Yes } \\
(n=85)\end{array}$ \\
\hline Orientation & Orientation total & 0.09 & 0.05 & 0.14 & 0.22 & 0.01 & 0.09 & -0.01 & 0.13 & -0.05 & 0.05 & 0.10 & 0.14 & 0.06 \\
\hline \multirow[t]{3}{*}{ Registration } & DS total score & 0.13 & 0.15 & 0.10 & 0.12 & 0.15 & 0.15 & 0.13 & 0.02 & $0.28^{\mathrm{a}}$ & 0.03 & $0.28^{\mathrm{a}}$ & 0.03 & $0.24^{\mathrm{a}}$ \\
\hline & DS forward & 0.14 & 0.13 & 0.14 & 0.11 & 0.16 & 0.15 & 0.15 & 0.01 & $0.29^{\mathrm{a}}$ & 0.01 & $0.29^{\mathrm{a}}$ & -0.02 & $0.30^{\mathrm{a}}$ \\
\hline & DS backward & 0.13 & 0.18 & 0.06 & 0.11 & 0.16 & 0.14 & 0.13 & 0.04 & 0.25 & 0.04 & 0.24 & 0.06 & 0.21 \\
\hline \multirow[t]{3}{*}{ Attention } & DS total score & $0.28^{\mathrm{a}}$ & $0.34^{\mathrm{a}}$ & 0.20 & $0.27^{\mathrm{a}}$ & $0.28^{\mathrm{a}}$ & $0.38^{\mathrm{a}}$ & -0.01 & 0.08 & $0.43^{\mathrm{a}}$ & $0.23^{\mathrm{a}}$ & $0.37^{\mathrm{a}}$ & $0.27^{\mathrm{a}}$ & $0.29^{\mathrm{a}}$ \\
\hline & DS forward & $0.26^{\mathrm{a}}$ & $0.31^{\mathrm{a}}$ & 0.16 & $0.33^{\mathrm{a}}$ & 0.20 & $0.32^{\mathrm{a}}$ & 0.02 & 0.09 & $0.37^{\mathrm{a}}$ & $0.22^{\mathrm{a}}$ & $0.31^{\mathrm{a}}$ & $0.25^{\mathrm{a}}$ & $0.27^{\mathrm{a}}$ \\
\hline & DS backward & $0.28^{\mathrm{a}}$ & $0.36^{\mathrm{a}}$ & 0.20 & 0.20 & $0.33^{\mathrm{a}}$ & $0.39^{\mathrm{a}}$ & -0.10 & 0.11 & $0.42^{\mathrm{a}}$ & $0.25^{\mathrm{a}}$ & $0.33^{\mathrm{a}}$ & $0.29^{\mathrm{a}}$ & $0.28^{\mathrm{a}}$ \\
\hline \multirow[t]{2}{*}{ Memory } & LM I & $0.16^{\mathrm{a}}$ & $0.23^{\mathrm{a}}$ & 0.11 & 0.17 & 0.16 & 0.11 & 0.07 & $0.19^{\mathrm{a}}$ & 0.05 & 0.16 & 0.14 & 0.15 & 0.17 \\
\hline & LM II & $0.23^{\mathrm{a}}$ & $0.30^{\mathrm{a}}$ & 0.18 & 0.22 & $0.25^{\mathrm{a}}$ & 0.18 & 0.13 & $0.25^{\mathrm{a}}$ & 0.15 & $0.21^{a}$ & 0.23 & 0.20 & $0.26^{\mathrm{a}}$ \\
\hline Language & COWA & $0.34^{\mathrm{a}}$ & $0.37^{\mathrm{a}}$ & $0.34^{\mathrm{a}}$ & $0.45^{\mathrm{a}}$ & $0.27^{\mathrm{a}}$ & $0.34^{\mathrm{a}}$ & 0.20 & $0.35^{\mathrm{a}}$ & 0.25 & $0.44^{\mathrm{a}}$ & 0.16 & $0.29^{\mathrm{a}}$ & $0.43^{\mathrm{a}}$ \\
\hline
\end{tabular}

MMSE, mini-mental status examination; COWA, controlled oral word association; DS, digit span; LM, logical memory, HS, high school.

${ }^{\mathrm{a}} P \leq 0.05$. 
Table 5 Correlations of MMSE domain scores with corresponding neuropsychological test by demographic variables, ABC study data

\begin{tabular}{|c|c|c|c|c|c|c|}
\hline \multirow[t]{2}{*}{ MMSE domain } & \multirow[t]{2}{*}{ Corresponding neuropsychological test } & \multirow[t]{2}{*}{ All patients } & \multicolumn{2}{|l|}{ Gender } & \multicolumn{2}{|l|}{ Age } \\
\hline & & & Male & Female & $<50$ & $\geq 50$ \\
\hline At Discharge: & & $(\mathrm{N}=61)$ & $(n=38)$ & $(n=23)$ & $(n=17)$ & $(n=44)$ \\
\hline \multirow[t]{3}{*}{ Attention } & Digit Span total score & $0.47^{\mathrm{a}}$ & $0.55^{\mathrm{a}}$ & 0.39 & $0.49^{\mathrm{a}}$ & $0.46^{\mathrm{a}}$ \\
\hline & Digit Span forward & 0.29 & 0.32 & 0.31 & 0.32 & 0.28 \\
\hline & Digit Span backward & $0.45^{\mathrm{a}}$ & $0.53^{\mathrm{a}}$ & 0.34 & $0.63^{\mathrm{a}}$ & $0.41^{\mathrm{a}}$ \\
\hline 3 Months: & & $(n=68-69)$ & $(n=37)$ & $(n=31-32)$ & $(n=19)$ & $(n=49-50)$ \\
\hline \multirow[t]{3}{*}{ Attention } & Digit Span total score & $0.34^{\mathrm{a}}$ & $0.38^{\mathrm{a}}$ & 0.29 & -0.30 & $0.42^{\mathrm{a}}$ \\
\hline & Digit Span forward & 0.20 & 0.27 & 0.12 & -0.16 & 0.22 \\
\hline & Digit Span backward & $0.39^{\mathrm{a}}$ & $0.35^{\mathrm{a}}$ & $0.45^{\mathrm{a}}$ & -0.41 & $0.51^{\mathrm{a}}$ \\
\hline 12 Months: & & $(n=45-47)$ & $(n=21-22)$ & $(n=24-25)$ & $(n=10)$ & $(n=35-37)$ \\
\hline \multirow[t]{3}{*}{ Attention } & Digit Span total score & $0.47^{a}$ & $0.48^{\mathrm{a}}$ & $0.47^{\mathrm{a}}$ & 0.62 & $0.45^{\mathrm{a}}$ \\
\hline & Digit Span forward & 0.20 & 0.31 & 0.12 & 0.50 & 0.17 \\
\hline & Digit Span backward & $0.49^{\mathrm{a}}$ & $0.57^{\mathrm{a}}$ & 0.33 & 0.32 & $0.52^{\mathrm{a}}$ \\
\hline
\end{tabular}

MMSE, mini-mental status examination.

${ }^{\mathrm{a}} P \leq 0.05$.

The MMSE is characterized by highly selective coverage of cognitive domains and does not evaluate learning, delayed memory, processing speed and executive function, among other cognitive domains. Many of these omitted cognitive domains reflect the frontal-subcortical white matter-mediated impairments known to occur in critical illness, and commonly identified in ICU survivors $[4,14,27,31,56]$. Hence, their omission in a short screening test is problematic. As we learn more about the granular and specific aspects of cognitive impairment in acute respiratory failure survivors, better cognitive screening tools tailored to this population could be developed.

Our study is among the first to test the validity of the MMSE in acute respiratory failure survivors. Strengths of our study include the ability to examine overall and domain-specific performance of the MMSE compared to a battery of neuropsychological tests administered concurrently. The ALTOS study provided a relatively large multicenter sample, which employed both a screening and neuropsychological test battery, and data from two time points. Inclusion of the $A B C$ study allowed us to test the generalizability of our findings in an independent cohort using similar neuropsychological tests. Our study also has potential limitations. First, we were not able to fully replicate all of the analyses from the ALTOS data using the $A B C$ study data due to the different follow-up time points and neuropsychological tests used. However, the available comparisons (overall cognitive impairment and attention) demonstrated similar results to the ALTOS study, helping increase confidence in the generalizability of our findings, especially since the studies used different neuropsychological tests. Further, participants in the $\mathrm{ABC}$ study had a high baseline psychiatric comorbidity, which is higher than the prevalence observed in other ICU cohorts [57,58]. However, while the prevalence of baseline psychiatric comorbidities was different between the two studies ( $42 \%$ for the ALTOS study and $74 \%$ for the ABC study), the results of the analyses of the MMSE were similar. Second, despite the relatively large sample size, secondary analyses conducted using binary patient categories had smaller sample sizes and may have reduced power to detect true difference between subgroups. Third, the MMSE and neuropsychological tests were administered using different methods in the ALTOS study (phone versus in-person), potentially contributing to the differences. However, the MMSE is validated for telephone administration, minimizing this concern [34]. Moreover, inperson administration was used for all testing in the $A B C$ study and demonstrated similar results to the ALTOS study. Finally, the MMSE total score is validated to identify cognitive impairment; however, the domain scores have not been validated as standalone measures. Our assessment of the correlations between the MMSE domains and the corresponding neuropsychological tests should be taken within context of overall study findings, and not as a recommendation to only administer specific domains of the MMSE.

\section{Conclusions}

Identifying valid, reliable and feasible screening tools is vital for evaluating long-term cognitive impairments commonly occurring in acute respiratory failure survivors. The MMSE, one of the most commonly used cognitive screening tools, demonstrated only fair agreement and poor sensitivity when compared to concurrently administered neuropsychological 
test batteries in acute respiratory failure survivors during their first year of recovery. Our findings do not support use of the MMSE as a screening tool for cognitive impairment in this patient population. Evaluation of alternative cognitive screening tests, either alone or in combination with other measures, is needed in acute respiratory failure survivors.

\section{Key messages}

- The Mini-Mental Status Examination (MMSE) is widely used as a screening tool for cognitive impairment in other patient populations, but its ability to detect impairment in survivors of acute respiratory failure is unclear.

- In survivors of acute respiratory failure, the MMSE (compared to a detailed neuropsychological test battery) demonstrated moderate agreement in detecting overall cognitive impairment, with excellent specificity but poor sensitivity.

- The area under the receiver operating characteristics curve indicates the MMSE had only fair discrimination in detecting cognitive impairment at 6 and 12 months.

- Our findings were not influenced by patient characteristics (age, gender or education), psychiatric disorders or timing of longitudinal follow-up assessment.

- MMSE results in survivors of acute respiratory failure should be interpreted with caution.

\section{Abbreviations \\ ABC: Awakening and Breathing Controlled Study; ALTOS: ARDSNet Long Term Outcomes Study; ICU: Intensive care unit; MMSE: Mini-Mental State Examination.}

\section{Competing interests}

TD Girard has received payment for lectures from Hospira. C Hough received consulting fees from High Point Pharmaceuticals, High Point, NC. EW Ely received consulting fees from Hospira, Abbott Laboratories, and Orion. The authors declare that they have no other competing interests.

\section{Authors' contributions}

All authors contributed to the conception and/or design of this study. DMN, VDD, TDG, PEM, CLH, JCJ, PAM-T, EW and ROH contributed to the acquisition of data. ERP, MH and KSC contributed to the analysis of data and all authors contributed to the interpretation of data. ERP and $\mathrm{ROH}$ drafted the manuscript, and all authors critically revised it for important intellectual content and approved the final version to be submitted.

\footnotetext{
Acknowledgements

ERP takes responsibility for the content of the manuscript including the data and analysis.

This research was supported by the NIH (grant numbers: R24HL111895, R01HL091760, R01HL091760-02S1, R01HL096504 and K23AG034257), the Johns Hopkins Institute for Clinical and Translational Research (ICTR) (grant number: UL1 TR 000424-06) and the ALTA and EDEN/OMEGA trials (contracts for sites participating in this study: HSN268200536170C, HHSN268200536171C, HHSN268200536173C, HHSN268200536174C, HSN268200536175C and HHSN268200536179C). The sponsors had no role in the data acquisition, analysis or preparation of the manuscript. We thank all patients and their proxies who participated in the study. We acknowledge our dedicated research staff, including the following who
}

assisted with data collection, training and quality assurance and/or data management: Lindsay Anderson, Ellen Caldwell, Nancy Ciesla, William Flickinger, Jacqueline Flynn, Jonathan Gellar, Stephanie Gundel, John Keenan, Christopher Mayhew, Melissa McCullough, Jessica McCurley, Mardee Merrill, Laura Methvin, Kristin Sepulveda, Kelly Swanson, Elizabeth Vayda and Cassie Wicken.

Investigators and research staff from the National Heart, Lung, and Blood Institute Acute Respiratory Distress Syndrome (ARDS) Clinical Trials Network sites that participated in this follow-up study: University of Washington, Harborview (*L Hudson, S Gundel, *C Hough, M Neff, K Sims, A Ungar, T Watkins); Johns Hopkins University ( ${ }^{*}$ R Brower, H Fessler, D Hager, P MendezTellez, D Needham, K Oakjones); Johns Hopkins Bayview Medical Center (J Sevransky, A Workneh); University of Maryland (C Shanholtz, D Herr, H Howes, G Netzer, P Rock, A Sampaio, J Titus); Union Memorial Hospital (P Sloane, T Beck, D Highfield, S King); Washington Hospital Center (B Lee, N Bolouri); Vanderbilt University ( ${ }^{*}$ AP Wheeler, GR Bernard, M Hays, S Mogan, TW Rice); Wake Forest University ( ${ }^{*}$ RD Hite, A Harvey, PE Morris, M Ragusky); Intermountain Medical Center ( ${ }^{*}$ A Morris, ${ }^{*}$ C Grissom, A Austin, S Barney, S Brown, J Ferguson, H Gallo, T Graydon, E Hirshberg, A Jephson, N Kumar, M Lanspa, R Miller, D Murphy, J Orme, A Stowe, L Struck, F Thomas, D Ward,); LDS Hospital (P Bailey, W Beninati, L Bezdjian, T Clemmer, S Rimkus, R Tanaka, L Weaver); McKay Dee Hospital (C Lawton, D Hanselman); Utah Valley Regional Medical Center (K Sundar, W Alward, C Bishop, D Eckley, D Harris, T Hill, B Jensen, K Ludwig, D Nielsen, M Pearce). Clinical Coordinating Center: Massachusetts General Hospital and Harvard Medical School ( ${ }^{*}$ D Schoenfeld, N Dong, M Guha, E Hammond, P Lazar, R Morse, C Oldmixon, N Ringwood, E Smoot, BT Thompson, R Wilson). National Heart, Lung and Blood Institute: A Harabin, S Bredow, M Waclawiw, G Weinmann. Data and Safety Monitoring Board: RG Spragg (chair), A Slutsky, M Levy, B Markovitz, E Petkova, C Weijer. Protocol Review Committee: J Sznajder (chair), M Begg, L Gilbert-McClain, E Israel, J Lewis, S McClave, P Parsons.

*Principal investigator.

\section{Author details}

'Department of Health Policy and Management, Johns Hopkins Bloomberg School of Public Health, 615 N. Wolfe Street, Baltimore, MD 21205, USA.

${ }^{2}$ Outcomes after Critical IIIness and Surgery Group, Johns Hopkins University, 1830 E Monument Street, Baltimore, MD 21205, USA. ${ }^{3}$ Division of Pulmonary and Critical Care Medicine, Johns Hopkins School of Medicine, 1830 E Monument Street, Baltimore, MD 21205, USA. ${ }^{4}$ Division of Allergy, Pulmonary, and Critical Care Medicine, Department of Medicine, Vanderbilt University School of Medicine, D-3100, Medical Center North, Nashville, TN 37232, USA. ${ }^{5}$ Center for Health Services Research, Department of Medicine, Vanderbilt University School of Medicine, 2215 Garland Ave, Nashville, TN 37232, USA. ${ }^{6}$ Center for Quality of Aging, Department of Medicine, Vanderbilt University School of Medicine, 2215 Garland Ave, Nashville, TN 37232, USA. ${ }^{7}$ Geriatric Research, Education and Clinical Center Service, Department of Veterans Affairs Medical Center, Tennessee Valley Healthcare System, 1310 24th Ave. S, Nashville, TN 37212, USA. ${ }^{8}$ Section on Pulmonary, Critical Care, Allergy and Immunologic Diseases, School of Medicine, Wake Forest University, Winston-Salem, NC 27157, USA. ${ }^{9}$ Division of Pulmonary and Critical Care Medicine, Harborview Medical Center, University of Washington, Campus Box 356522, Seattle, WA 98195, USA. ${ }^{10}$ Department of Anesthesiology and Critical Care Medicine, School of Medicine, Johns Hopkins University, 600 North Wolfe Street, Baltimore, MD 21287, USA. ${ }^{11}$ Department of Physical Medicine and Rehabilitation, Johns Hopkins School of Medicine, 1830 E Monument Street, Baltimore, MD 21205, USA. ${ }^{12}$ Division of Pulmonary and Critical Care Medicine, Intermountain Medical Center, 5121 Cottonwood Street, Murray, UT 84107, USA. ${ }^{13}$ Psychology Department and Neuroscience Center, Brigham Young University, 1022 SWKT, Provo, UT 84602, USA. ${ }^{14}$ Center for Humanizing Critical Care, Intermountain Health Care, 5121 South Cottonwood Street, Murray, Utah 84157, USA.

Received: 5 February 2015 Accepted: 20 April 2015

Published online: 05 May 2015

\section{References}

1. Needham DM, Davidson J, Cohen H, Hopkins RO, Weinert C, Wunsch H, et al. Improving long-term outcomes after discharge from intensive care unit: report from a stakeholders' conference. Crit Care Med. 2012;40:502-9. 
2. Elliott D, Davidson JE, Harvey MA, Bemis-Dougherty A, Hopkins RO, Iwashyna TJ, et al. Exploring the scope of post-intensive care syndrome therapy and care: engagement of non-critical care providers and survivors in a second stakeholders meeting. Crit Care Med. 2014;42:2518-26.

3. Wolters AE, Slooter AJ, van der Kooi AW, van Dijk D. Cognitive impairment after intensive care unit admission: a systematic review. Intensive Care Med. 2013;39:376-86.

4. Pandharipande PP, Girard TD, Jackson JC, Morandi A, Thompson JL, Pun BT, et al. Long-term cognitive impairment after critical illness. N Engl J Med. 2013:369:1306-16.

5. Iwashyna TJ, Ely EW, Smith DM, Langa KM. Long-term cognitive impairment and functional disability among survivors of severe sepsis. JAMA. 2010;304:1787-94.

6. Ehlenbach WJ, Hough CL, Crane OK, Haneuse SJ, Carson SS, Curtis JR, et al. Association between acute care and critical illness hospitalization and cognitive function in older adults. JAMA. 2010;303:763-70.

7. Richards JE, Guillamondegui OD, Archer KR, Jackson JC, Ely EW, Obremskey WT. The association of reamed intramedullary nailing and long-term cognitive impairment. J Orthop Trauma. 2011;25:707-13.

8. Jackson JC, Obremskey W, Bauer R, Greevy R, Cotton BA, Anderson V, et al. Longterm cognitive, emotional, and functional outcomes in trauma intensive care unit survivors without intracranial hemorrhage. J Trauma. 2007;62:80-8.

9. Jackson JC, Archer KR, Bauer R, Abraham CM, Song Y, Greevey R, et al. A prospective investigation of long-term cognitive impairment and psychological distress in moderately versus severely injured trauma intensive care unit survivors without intracranial hemorrhage. J Trauma. 2011;71:860-6.

10. Guillamondegui OD, Richards JE, Ely EW, Jackson JC, Archer KR, Norris PR, et al. Does hypoxia affect intensive care unit delirium or long-term cognitive impairment after multiple trauma without intracranial hemorrhage? J Trauma. 2011;70:910-5.

11. Girard TD, Jackson JC, Pandharipande PP, Pun BT, Pun BT, Thompson JL, et al. Delirium as a predictor of long-term cognitive impairment in survivors of critical illness. Crit Care Med. 2010;38:1513-20.

12. Iwashyna TJ. Trajectories of recovery and dysfunction after acute illness, with implications for clinical trial design. Am J Respir Crit Care Med. 2012;186:302-4.

13. Brummel NE, Girard TD, Ely EW, Pandharipande PP, Morandi A, Hughes CG, et al. Feasibility and safety of early combined cognitive and physical therapy for critically ill medical and surgical patients: the Activity and Cognitive Therapy in ICU (ACT-ICU) trial. Intensive Care Med. 2014;40:370-9.

14. Jackson JC, Ely EW, Morey MC, Morey MC, Anderson VM, Denne LB, et al. Cognitive and physical rehabilitation of intensive care unit survivors: results of the RETURN randomized controlled pilot investigation. Crit Care Med. 2012;40:1088-97.

15. Lin JS, O'Connor E, Rossom RC, Perdue LA, Eckstrom E. Screening for cognitive impairment in older adults: a systematic review for the U.S. Preventive Services Task Force. Ann Intern Med. 2013;159:601-12.

16. Tangalos EG, Smith GE, Ivnik RJ, Petersen RC, Kokmen E, Kurland LT, et al. The Mini-Mental State Examination in general medical practice: clinical utility and acceptance. Mayo Clin Proc. 1996;71:829-37.

17. Woon FL, Dunn CB, Hopkins RO. Predicting cognitive sequelae in survivors of critical illness with cognitive screening tests. Am J Respir Crit Care Med. 2012;186:333-40

18. Jackson JC, Hart RP, Gordon SM, Shintani A, Truman B, May L, et al. Sixmonth neuropsychological outcome of medical intensive care unit patients. Crit Care Med. 2003;31:1226-34.

19. Needham DM, Dinglas VD, Bienvenu OJ, Colantuoni E, Wozniak AW, Rice TW, et al. One year outcomes in patients with acute lung injury randomised to initial trophic or full enteral feeding: prospective follow-up of EDEN randomised trial. BMJ. 2013;346:f1532.

20. Peek GJ, Mugford M, Tiruvoipati R, Wilson A, Allen E, Thalanany MM, et al. Efficacy and economic assessment of conventional ventilatory support versus extracorporeal membrane oxygenation for severe adult respiratory failure (CESAR): a multicentre randomised controlled trial. Lancet. 2009;374:1351-63.

21. Sacanella E, Pérez-Castejón JM, Nicolás JM, Masanés F, Navarro M, Castro P, et al. Functional status and quality of life 12 months after discharge from a medical ICU in healthy elderly patients: a prospective observational study. Crit Care. 2011;15:R105.

22. Unroe M, Kahn JM, Carson SS, Govert JA, Martinu T, Sathy SJ, et al. One-year trajectories of care and resource utilization for recipients of prolonged mechanical ventilation: a cohort study. Ann Intern Med. 2010;153:167-75.
23. Radtke FM, Franck M, Herbig TS, Papkalla N, Kleinwaechter R, Kork F, et al. Incidence and risk factors for cognitive dysfunction in patients with severe systemic disease. J Int Med Res. 2012;40:612-20.

24. Torgersen J, Hole JF, Kvåle R, Wentzel-Larsen T, Flaatten H. Cognitive impairments after critical illness. Acta Anaesthesiol Scand. 2011;55:1044-51.

25. Kim SY, Lim TS, Lee HY, Moon SY. Clustering mild cognitive impairment by mini-mental state examination. Neurol Sci. 2014;35:1353-8.

26. Saczynski JS, Marcantonio ER, Quach L, Fong TG, Gross A, Inouye SK, et al. Cognitive trajectories after postoperative delirium. N Engl J Med. 2012;367:30-9.

27. Needham DM, Dinglas VD, Morris PE, Jackson JC, Hough CL, Mendez-Tellez PA, et al. Physical and cognitive performance of patients with acute lung injury 1 year after initial trophic versus full enteral feeding. EDEN trial follow-up. Am J Respir Crit Care Med. 2013;188:567-76.

28. National Heart, Lung, and Blood Institute Acute Respiratory Distress Syndrome (ARDS) Clinical Trials Network, Matthay MA, Brower RG, Carson S, Douglas IS, Eisner M, et al. Randomized, placebo-controlled clinical trial of an aerosolized $\beta_{2}$-agonist for treatment of acute lung injury. Am J Respir Crit Care Med. 2011;184:561-8.

29. Rice TW, Wheeler AP, Thompson BT, de Boisblanc BP, Steingrub J, Rock P, et al. Enteral omega-3 fatty acid, gamma-linolenic acid, and antioxidant supplementation in acute lung injury. JAMA. 2011;306:1574-81.

30. Heart N, Lung, and Blood Institute Acute Respiratory Distress Syndrome (ARDS) Clinical Trials Network, Rice TW, Wheeler AP, Thompson BT, Steingrub J, Hite RD, et al. Initial trophic vs full enteral feeding in patients with acute lung injury: the EDEN randomized trial. JAMA. 2012;307:795-803

31. Jackson JC, Girard TD, Gordon SM, Thompson JL, Shintani AK, Thomason JW, et al. Long-term cognitive and psychological outcomes in the awakening and breathing controlled trial. Am J Respir Crit Care Med. 2010;182:183-91.

32. Charlson ME, Pompei P, Ales KL, MacKenzie CR. A new method of classifying prognostic comorbidity in longitudinal studies: development and validation. J Chronic Dis. 1987:40:373-83.

33. Newkirk LA, Kim JM, Thompson JM, Tinklenberg JR, Yesavage JA, Taylor JL. Validation of a 26-point telephone version of the Mini-Mental State Examination. J Geriatr Psychiatry Neurol. 2004;17:81-7.

34. Folstein MF, Folstein SE, McHugh PR. Mini-mental state. A practical method for grading the cognitive state of patients for the clinician. J Psychiatr Res. 1975;12:189-98.

35. Tulsky D, Zhu J. WAIS-III WMS-III Technical manual. San Antonio, TX: The Psychological Corporation, Harcourt Brace \& Company; 1977.

36. Ross TP, Calhoun E, Cox T, Wenner C, Kono W, Pleasant M. The reliability and validity of qualitative scores for the Controlled Oral Word Association Test. Arch Clin Neuropsychol. 2007;22:475-88.

37. Ruff RM, Light RH, Parker SB, Levin HS. Benton Controlled Oral Word Association Test: reliability and updated norms. Arch Clin Neuropsychol. 1996;11:329-38.

38. Kiernan RJ, Mueller J, Langston JW, Van Dyke C. The Neurobehavioral Cognitive Status Examination: a brief but quantitative approach to cognitive assessment. Ann Intern Med. 1987;107:481-5.

39. Wechsler D. Wechsler Memory Scale. 3rd ed. San Antonio, TX: The Psychological Corporation; 1997.

40. Heaton RK, Miller SW, Taylor JR, Grant I. Comprehensive norms for an expanded Halstead Reitan Battery: demographically adjusted neuropsychological norms for African American and Caucasian adults. Professional Manual. Lutz, FL: Psychological Assessment Resources Inc:; 2004

41. Lezak MD. Neuropsychological assessment. 3rd ed. New York: Oxford University Press; 1995.

42. Bienvenu OJ, Colantuoni E, Mendez-Tellez PA, Dinglas VD, Shanholtz C, Husain N, et al. Depressive symptoms and impaired physical function after acute lung injury: a 2-year longitudinal study. Am J Respir Crit Care Med. 2012;185:517-24.

43. Zigmond AS, Snaith RP. The hospital anxiety and depression scale. Acta Psychiatr Scand. 1983;67:361-70.

44. Rey A. L'examen psychologique dans les cas d'encephalopathie traumatique. Arch Psychol. 1941;28:286-340.

45. Rey A. L'examen clinique en psychologie. Paris: Presses Universitaites de France; 1964.

46. Reitan RM, Wolfson D. The Halstead Reitan neuropsychological test battery. Tuscon, AZ: Neuropsychology Press; 1985.

47. Spreen O, Benton AL. Neurosensory Center Comprehensive Examination for Aphasis (NCCEA). Victoria: University of Victoria Neuropsychological Laboratory; 1969. 
48. Kukull WA, Larson EB, Teri L, Bowen J, McCormick W, Pfanschmidt ML. The Mini-Mental State Examination score and the clinical diagnosis of dementia. J Clin Epidemiol. 1994;47:1061-7.

49. Kamath PS, Wiesner RH, Malinchoc M, Kremers W, Therneau TM, Kosberg CL, et al. A model to predict survival in patients with end-stage liver disease. Hepatology. 2001;33:464-70.

50. Burker EJ, Blumenthal JA, Feldman M, Thyrum E, Mahanna E, White W, et al. The Mini Mental State Exam as a predictor of neuropsychological functioning after cardiac surgery. Int J Psychiatry Med. 1995;25:263-76.

51. Galioto R, Garcia S, Spitznagel MB, Strain G, Devlin M, Crosby RD, et al. The Mini-Mental State Exam (MMSE) is not sensitive to cognitive impairment in bariatric surgery candidates. Surg Obes Relat Dis. 2014;10:553-7.

52. Wilcox ME, Brummel NE, Archer K, Ely EW, Jackson JC, Hopkins RO. Cognitive dysfunction in ICU patients: risk factors, predictors, and rehabilitation interventions. Crit Care Med. 2013;41:S81-98.

53. Nasreddine ZS, Phillips NA, Bédirian V, Charbonneau S, Whitehead V, Collin I, et al. The Montreal Cognitive Assessment, MoCA: a brief screening tool for mild cognitive impairment. J Am Geriatr Soc. 2005;53:695-9.

54. Roalf DR, Moberg PJ, Xie SX, Wolk DA, Moelter ST, Arnold SE. Comparative accuracies of two common screening instruments for classification of Alzheimer's disease, mild cognitive impairment, and healthy aging. Alzheimers Dement. 2013:9:529-37.

55. Kim JW, Lee DY, Seo EH, Sohn BK, Choe YM, Kim SG, et al. Improvement of screening accuracy of Mini-Mental State Examination for mild cognitive impairment and non-Alzheimer's disease dementia by supplementation of verbal fluency performance. Psychiatry Investig. 2014;11:44-51.

56. Hopkins RO, Weaver LK, Collingridge D, Parkinson RB, Chan KJ, Orme Jr JF. Two-year cognitive, emotional, and quality-of-life outcomes in acute respiratory distress syndrome. Am J Respir Crit Care Med. 2005;171:340-7.

57. Jackson JC, Pandharipande PP, Girard TD, Brummel NE, Thompson JL, Hughes CG, et al. Depression, post-traumatic stress disorder, and functional disability in survivors of critical illness in the BRAIN-ICU study: a longitudinal cohort study. Lancet Respir Med. 2014;2:369-79.

58. Dowdy DW, Bienvenu OJ, Dinglas VD, Mendez-Tellez PA, Sevransky J, Shanholtz C, et al. Are intensive care factors associated with depressive symptoms 6 months after acute lung injury? Crit Care Med. 2009;37:1702-7.

\section{Submit your next manuscript to BioMed Central and take full advantage of:}

- Convenient online submission

- Thorough peer review

- No space constraints or color figure charges

- Immediate publication on acceptance

- Inclusion in PubMed, CAS, Scopus and Google Scholar

- Research which is freely available for redistribution 